\title{
Characterization of curd grain size and shape by 2-dimensional image analysis during the cheesemaking process in artisanal sheep dairies
}

\author{
Ane Aldalur, María Ángeles Bustamante, and Luis Javier R. Barron* \\ Lactiker Research Group, Faculty of Pharmacy, University of the Basque Country (UPV/EHU), Paseo de la Universidad 7 , \\ 01006 Vitoria-Gasteiz, Spain
}

\begin{abstract}
The size and shape of curd grains are the most important parameters used by cheesemakers to decide when to end the cutting or stirring processes during cheesemaking. Thus, 2-dimensional image analysis was used to measure the characteristics of curd grains in commercial cheese productions carried out by artisanal sheep dairies. Dairies used different technical settings for cutting and stirring steps, causing differences in the size and shape of curd grains. A linear relationship between total revolutions used for cutting and stirring and curd particle size was established. However, particle size distributions after curd cutting and stirring were highly heterogeneous. Actual cheese yield was correlated with particle size and cutting revolutions, whereas curd grain shape and fat loss were associated with stirring conditions by a multivariate approach. Image analysis of the size and shape of curd grains gives useful information for determining characteristics related to cheese yield and quality and may contribute to improving and controlling the cheesemaking process in small artisanal dairies.
\end{abstract}

Key words: image analysis, cheese yield, artisanal sheep dairy, commercial cheese production

\section{INTRODUCTION}

The measurement of the size and shape of curd particles as well as the particle size distribution (PSD) is an effective tool for controlling the cutting and stirring steps during the cheesemaking process. Previous studies have investigated the effect of cutting and stirring on curd syneresis, cheese yield, and protein and fat losses in the whey using the sieving method for curd PSD measurement (Kosikowski, 1963; Johnston et al., 1991; Akkerman, 1992; Johnston et al., 1998; Everard et al., 2008; Mateo et al., 2010). This method based on

Received June 8, 2018.

Accepted November 4, 2018.

*Corresponding author: luisjavier.rbarron@ehu.eus passing the curd grains through a battery of different size mesh sieves showed strong deviations (approximately 20 times) and limitations (maximum 5 sieves) for separating grains with different sizes (Johnston et al., 1991; Igathinathane et al., 2009). Furthermore, the sieving method has other difficulties due to stickiness of the curd grains, lump formations, and breakage of curd particles during the mechanical handling (Jablonka and Munro, 1985; Johnston et al., 1991). This makes it difficult to compare PSD data among different studies or to calculate parameters to describe PSD curves accurately. Recently, other authors have used a 2-dimensional image analysis method to study the curd grains during the cheesemaking of some Italian cheeses (Iezzi et al., 2012). Image analysis enables a more detailed measurement of curd PSD and the management of accurate data of different particle size and shape features. This method allows ampler information and looking for new variables for PSD and particle characterization (Du and Sun, 2004; Igathinathane et al., 2009).

Most previous studies have focused on particle size to characterize curd grains during the cheesemaking process, but particle shape can be as important as size because it describes the particle more thoroughly; accordingly, particle shape can help develop a better understanding of curd grain syneresis during cutting and stirring. Kammerlehner (2009) described the shape of the curd grains after stirring as similar to that of seeds and fruits, but, to the best of our knowledge, very few quantitative data are available on the shape description of curd particles (Rüegg and Moor, 1987).

Small artisanal dairies generally use manual or semiautomatic vats for cutting and stirring the curd. Therefore, cheesemakers are guided by their own experience to choose the cutting and stirring parameters, but it is crucial for each dairy to determine the optimal processing conditions for its facilities and for the cheese type that is being manufactured (Kammerlehner, 2009). This study monitored the cheesemaking process carried out in small artisanal dairies belonging to the Idiazabal cheese Protected Denomination of Origin (PDO). This cheese is a semihard variety made from raw sheep milk 
in the Basque Country and Navarre (northern Spain), where most cheese dairies are of small production volume and artisan type (Idiazabal PDO, 2017). The Idiazabal PDO regulation (Ministerio de Agricultura, Pesca y Alimentación, 1993) indicates briefly that the curd grains after the cutting step must achieve a diameter of 5 to $10 \mathrm{~mm}$ and afterward the grains must be stirred until a maximum temperature of $38^{\circ} \mathrm{C}$. This regulation does not determine the characteristics of the final curd grains after stirring, even though it is a more relevant parameter to cheese quality and yield than the one currently described (Dejmek and Walstra, 2004; Everard et al., 2008).

Therefore, the aim of the present study was to investigate the changes in particle size and shape that occurred during the curd grain syneresis after the cutting and stirring steps in small artisanal sheep dairies using 2-dimensional image analysis. Specific particle shape parameters were described for the first time in curd grain characterization, and the relationships between particle size and shape, cheese yield, and technological parameters used for the cutting and stirring were investigated.

\section{MATERIALS AND METHODS}

\section{Artisanal Dairies and Commercial Cheese Productions}

Eight Idiazabal PDO small artisanal dairies participated in the study. Three commercial cheese productions made on different days were monitored in each dairy during the cheese processing season from March to June. The facilities in the artisanal dairies included automatic milking machines, milk cold storage tanks, hydraulic presses, and controlled ripening chambers. All dairies used stainless steel vats (from 300 to 1,500 L) with heating and agitation systems including thermal sensors and potentiometers for the measurement of temperature and rotation speed of knives and stirrers, respectively. Small dairies carried out 1 cheese production per day. All the dairies, except dairy 1, used open oval-shaped vats, which had 1 or 2 axes of rotation where stirrers or cutting frames were placed. The shafts worked in circular motion (in the same or opposite direction when the 2 axes worked at the same time), but shifted from side to side of the vat while rotation occurred to prevent demixing of the curd. Cutting frames were equipped with 32 to 42 metallic or plastic wires in vertical alone or separately arranged vertical and horizontal positions with a gap of $2 \mathrm{~cm}$ between wires. For stirring, helix- or irregular-shaped metal paddles were totally submerged in the curd and whey mixture.
Dairy 1 was an exception, as it used an open double-O shaped vat with 2 fixed axes, equipped with vertical blade-cutters that were transformed into stirrers when the desired curd grain size was obtained during the cutting. The blades were separated by $6 \mathrm{~cm}$ and were sharp in the rotation direction when the cutting was performed and dull in the opposite direction.

The cheeses were manufactured according to the specifications approved by the Idiazabal PDO Regulatory Council (Ministerio de Agricultura, Pesca y Alimentación, 1993) from raw Latxa sheep milk. Depending on the production month and individual dairy, the commercial cheeses were made with bulk milk from 2 to 5 milkings, and the raw milk was stored at 3 to $8^{\circ} \mathrm{C}$ for an average time of $34 \mathrm{~h}$ before cheesemaking. Briefly, raw sheep milk was heated and a commercial homofermentative starter culture (Choozit, DuPont NHIB Ibérica S.L., Barcelona, Spain) was added when the milk reached approximately $25^{\circ} \mathrm{C}$. An adequate amount of commercial rennet or artisanal lamb rennet paste (Bustamante et al., 2000) was added to coagulate the milk at approximately $30^{\circ} \mathrm{C}$. Once the milk was coagulated, the curd was cut into grains at a constant temperature of approximately $30^{\circ} \mathrm{C}$; immediately after, the curd grains were stirred until approximately $36^{\circ} \mathrm{C}$ was reached. The time and rotation speed used for cutting and stirring depended on the dairy, and these parameters were not specified in the Idiazabal PDO regulation (European Commission, 2015). The whey was initially removed by manually pressing the curd grains in the vat and the formed paste was introduced in plastic molds. Afterward, cheeses were pressed at approximately $20^{\circ} \mathrm{C}$ for 3 to $7 \mathrm{~h}$ at 1.5 to $3.5 \mathrm{~kg} / \mathrm{cm}^{2}$, placed in saturated sodium chloride brine at approximately $10^{\circ} \mathrm{C}$ for 10 to $24 \mathrm{~h}$, and ripened at 8 to $12^{\circ} \mathrm{C}$ and $85 \%$ relative humidity for at least 2 mo.

\section{Milk and Curd Grain Sampling}

One sample $(0.5 \mathrm{~L})$ of bulk raw milk was taken from the vat before cheesemaking commenced and transported to the laboratory in a portable cooler. Subsamples of $50 \mathrm{~mL}$ were stored in screw-capped plastic containers at $-80^{\circ} \mathrm{C}$. Curd grains were sampled following an adapted method from Iezzi et al. (2012) using a round steel mesh sieve $22 \mathrm{~cm}$ in diameter and with $0.43-\mathrm{mm}$ mesh openings. The sieve was submerged to a depth approximately halfway between the top and bottom of the vat right after the end of cutting [fresh curd grain (FCG)] and stirring [stirred curd grain (SCG)] and before letting the curd grains settle. The sampling took from 3 to $5 \mathrm{~s}$ and curd grains were extracted by draining the excess amount of whey. The granules were 
scattered on a $210-\times 297-\mathrm{mm}^{2}$ black plastic sheet and disjoined carefully using a palette knife. This procedure prevents the formation of lumps that distort the size and shape of the grains and hinder image analysis. Photographs were taken within the first $5 \mathrm{~min}$ after extracting the curd grains from the vat because, as syneresis continued, especially in the fresh curd grains, the image had to be taken as fast as possible to avoid changes in the extracted curd grains. The FCG and SCG were sampled for each cheese production.

\section{Physicochemical and Technical Determinations}

Milk and cheese fat was determined in duplicate by Gerber and Van Gulik methods (ISO/IDF, 2008a,b), respectively, using a Lacter centrifuge (Orto Alresa, Aljavir, Madrid, Spain). Milk and cheese protein was analyzed by Kjeldahl method (ISO/IDF, 2008c, 2014) using a Kjeltec 2100 distillation unit (Foss, Höganäs, Sweden). Cheese DM was measured by drying the samples overnight at $102^{\circ} \mathrm{C}$ (ISO/IDF, 2004). Curd pH was measured in triplicate in situ at $20^{\circ} \mathrm{C}$ using a GLP21 pH-Meter (Crison, Alella, Spain). Milk volume (L) used for cheese production was measured in each artisanal dairy using flowmeters with mean precision values of $\pm 0.15 \%$. Actual cheese yield ( $\mathrm{kg}$ of cheese/100 L of milk) per vat was estimated as the ratio between the total weight of fresh cheeses after pressing and before brining and the milk volume used in the vat. Commercial weighting scales with mean precision value of $\pm 1 \mathrm{~g}$ available in the dairies were used. Adjusted cheese yield $\left(Y_{c a}\right)$ was defined as the moisture-adjusted cheese yield per $100 \mathrm{~L}$ of cheese milk adjusted to reference levels of fat $(6.8 \%)$ and protein $(5.30 \%)$ and was calculated using the equation 1 described by Guinee et al. (2006):

$$
\begin{gathered}
Y_{c a}=Y_{a} \times\left[\left(F_{r}+P_{r}\right) /\left(F_{c}+P_{c}\right)\right] \\
\times\left[\left(100-M_{a}\right) /\left(100-M_{r}\right)\right],
\end{gathered}
$$

where $Y_{a}$ is the actual cheese yield; $F_{r}$ and $P_{r}$ are the percentages of fat and protein in the reference cheese milk; $F_{c}$ and $P_{c}$ are the actual fat and protein contents of the cheese milk; and $M_{a}$ and $M_{r}$ are the actual and reference (42.5\%) moisture contents of cheese, respectively. Adjusted cheese yield was used to estimate the effect of cheesemaking conditions on cheese yield minimizing the intra- and interdairy variability in milk composition and cheese moisture during the cheese production season. The amount of fat lost $(\% \mathrm{FL})$ in the whey on milk basis was calculated as described in equation 2 (Guinee et al., 2006):

$$
\% \mathrm{FL}=\left[\left(\mathrm{W}_{\mathrm{W}} \times \mathrm{W}_{\mathrm{F}}\right) /\left(\mathrm{M}_{\mathrm{W}} \times \mathrm{M}_{\mathrm{F}}\right)\right] \times 100,
$$

where $\mathrm{W}_{\mathrm{W}}$ and $\mathrm{M}_{\mathrm{W}}$ were the weight $(\mathrm{kg})$ of the drained whey and milk, respectively, and $\mathrm{W}_{\mathrm{F}}$ and $\mathrm{M}_{\mathrm{F}}$ were the fat content (wt/wt) of whey and milk, respectively. The amount of whey produced during each processing was estimated as the mass balance between the amount of milk and that of fresh cheese produced per vat. The amount of milk per vat was calculated from the milk volume and density measured using a thermolactodensimeter (Gerber instruments AG, Effretikon, Switzerland). Time and temperature measurements for milk coagulation as well as curd cutting and stirring were monitored in situ with a Digitaler 2-fach timer digital chronometer (TFA Dostmann, Wertheim, Germany) and a N16B Glas mercury thermometer (Ludwig Schneider, Wertheim, Germany). Stirring temperature rate was established as the ratio between the difference of final and initial stirring temperature and time. Rotation speed for cutting and stirring was determined in triplicate from the time measurement that the tools (wire knives and stirrers) take on a full $360^{\circ}$ turn. Total revolutions used in each cheese production and artisanal dairy were calculated as the sum of rotation speed $\times$ time for cutting and stirring steps (Johnston et al., 1991).

\section{Curd Grain 2-Dimensional Image Analysis}

Photographs were taken with a D80 digital camera (Nikon Corporation, Tokyo, Japan) at a 2,896 $\times$ 1,944 pixel resolution and the curd grain images were analyzed with ImageJ software (National Institutes of Health, Bethesda, MD). The best-captured photograph per cheese production was used to analyze the curd grains. We used $215-\times 310-\mathrm{mm}^{2}$ graph paper (model 81718, Unipapel Int., Tres Cantos, Spain) as a reference to set the image scale. First, the quality of these images was improved by adjusting brightness and contrast to enhance the edge of each curd grain. The image was then thresholded, segmenting the picture into features of interest (curd grains) and background. As brightness conditions were not the same in the artisanal dairies, the thresholding step was customized for each photograph by taking into account the boundaries of the curd grains. Each granule that was clearly separated from one another or with a boundary easily detectable was selected. Before measuring the particle size and shape, the adjustment of the selection area to the curd grain was individually checked. Those particles with area $<1 \mathrm{~mm}^{2}$ were not taken into account in the curd grain image analysis.

The following size and shape parameters were measured: area $\left(\mathrm{mm}^{2}\right)$; perimeter $(\mathrm{mm})$, which is particularly useful for discriminating between particles with simple and complex shapes (Du and Sun, 2004); Feret's 
diameter $(\mathrm{mm})$, defined as the longest distance between any 2 points along the particle boundary; reciprocal aspect ratio (RAR), defined as where $\mathrm{A}$ and $\mathrm{B}$ are the major and minor axes of the best fitting ellipse of the particle, respectively, with a RAR value closer to 0 indicating elongated shape whereas closer to 1 indicates no flatness; rectangularity (RTY), defined as RTY = area/ $(\mathrm{h} \times \mathrm{w})$, where $\mathrm{h}$ and $\mathrm{w}$ are the height and the width of the smallest rectangle enclosing the particle, respectively, with RTY $=1$ indicating a perfect rectangle shape; circularity (CTY), defined as CTY = $4 \pi$ (area)/(perimeter $)^{2}$, with CTY values ranging from 1 to 0 indicating a perfect circle to an increasing elongated shape, respectively. The reduction of the size or shrinkage of the curd particles during stirring was used as an indicator of curd syneresis. Reduction rate mean values for area, perimeter, and Feret's diameter were defined as the ratio between FCG and SCG values for each parameter.

Particle size distribution analysis of FCG and SCG samples from each artisanal dairy cheese production was based on the area-based percentile dimensions from 5 to 95th. According to Igathinathane et al. (2009), the following PSD parameters based on percentile dimensions were calculated: uniformity index, with a percentage value close to 100 indicating homogeneous distribution; size range variation coefficient, with a percentage value furthest from 0 indicating heterogeneous distribution; relative span and coefficient of uniformity, with a value closer to 1 indicating homogeneous distribution; and graphic skewness and kurtosis, with different numerical values (Folk and Ward, 1957) to indicate the asymmetry and peakiness degree of the distribution, respectively.

\section{Statistical Analysis}

The IBM-SPSS Statistics software version 24.0 (New York, NY) was used for statistical analysis. The general linear model of ANOVA was used to study the effect of individual dairy (interdairy effect; $l=8$ ), cheese production (intradairy effect; $l=3$ ), and curd syneresis process $(l=2)$ on technical and analytical variables monitored during cheesemaking in the artisanal dairies. The fixed effects model $Y_{i j k}=\mu+D_{i}+C P_{j}+\varepsilon_{i j k}$ was applied to study simultaneously the effect of individual dairy $\left(D_{i}\right)$ and cheese production $\left(C P_{j}\right)$ on cheesemaking physicochemical and technical parameters, whereas the $(D \times C P)_{i j}$ interaction term was included in the model for FCG and SCG particle size and shape parameters. The milk fat-to-protein ratio was included as a covariate in the general linear model to study the actual cheese yield as dependent variable. The fixed effects model $Y_{i j k}$ $=\mu+D_{i}+S_{j}+(D \times S)_{i j}+\varepsilon_{i j k}$ was applied to study simultaneously the effect of curd syneresis process $\left(S_{j}\right)$ and $D_{i}$ on curd grain size and shape parameters. For those parameters with significant interaction term $(D$ $\times S)_{i j}$, an $F$-test of $S_{j}$ against $(D \times S)_{i j}$ was applied. Tukey's honest significant difference test was used to pairwise comparison for mean values from data with equality of variance, and Games-Howell post-hoc test was applied in the case of heteroscedastic data. MannWhitney U nonparametric test was applied to assess separately the $D_{i}$ effect on median values of particle size parameters in FCG and SCG samples, respectively. On the other hand, the nonparametric Kruskal-Wallis test was applied to investigate statistical differences in PSD parameters between FCG and SCG sample groups. Simple regression analysis was used to investigate the relationship between particle size parameters and the log of total revolutions used in the cheese productions, and Pearson correlation coefficient ( $\mathrm{r}$ ) was calculated for some pairs of variables. In addition, a principal component analysis was performed on self-scaling variables corresponding to curd grain size and shape parameters, cutting and stirring conditions, fat loss, and actual cheese yield to establish relationships among them. Kaiser criterion (eigenvalue $>1$ ) was applied to extract principal components and the distribution plot using the 2-dimensional coordinate system defined by the first 2 principal components was used to study the intra- and interdairy variability. Statistical significance was declared at $P \leq 0.05$.

\section{RESULTS AND DISCUSSION}

\section{Physicochemical and Technical Parameters Used for Cheesemaking}

Table 1 summarizes the most relevant physicochemical and technical parameters related to the curd syneresis process in artisanal dairies during the Idiazabal PDO cheese processing season from March to June. The main technical parameters monitored in artisanal dairies were related to time, temperature, and rotation speed used for curd cutting and stirring steps. As described above, cheesemakers used mechanized vats with different vat volume capacity; therefore, the amount of milk handled by the cheesemaker ranged from 270 to $1,330 \mathrm{~L}$. No significant differences $(P>0.05)$ were found among the artisanal dairies in the fat-to-protein ratio of milk, with grand mean values of 1.3. Accordingly, cheese composition parameters and actual and adjusted cheese yield did not show statistically significant differences $(P>$ $0.05)$ among dairies. However, variations in actual and adjusted cheese yield up to 3.8 and $2.4 \mathrm{~kg}$ of cheese $/ 100$ L of milk, respectively, were observed between some artisanal dairies (Table 1). These results indicated a 
large intra- and interdairy variability in the actual and adjusted cheese yield during the cheese processing season. On the other hand, significant differences $(P \leq$ 0.05 ) were observed in fat loss between dairy 1 and the others. Dairy 1, which used the most unique equipment and settings compared with the others, lost less than 6 $\mathrm{g} / 100 \mathrm{~g}$ of fat per cheese production whereas the others lost almost double (Table 1). No significant differences in fat loss $(P>0.05)$ were found among dairies 2 to 8 , but variations of $3 \mathrm{~g} / 100 \mathrm{~g}$ per cheese production were observed. These variations in fat loss were not reflected in cheese yield parameters but showed the opportunity for improving cheesemaking efficiency and compound recovery.

Regarding the coagulation step, Table 1 only shows the temperature and time used in each dairy for milk coagulation. The amount of rennet used in each dairy was not detailed because, as described above, most cheesemakers used lamb rennet paste prepared by themselves; thus, the amount of rennet was not a reflection of the coagulation capacity. Bustamante et al. (2000) characterized the coagulating activity of artisanal lamb rennet pastes prepared according to the traditional method for Idiazabal cheese and reported that milk coagulating activity varied between 155 and $363 \mathrm{U} / \mathrm{g}$ of tissue depending on the preparing conditions. Therefore, due to the difficulty of controlling these wide variations, the cheesemakers make the decision to start the cutting process according to the sensory observation of the curd consistency, which implied that coagulation time varied from 24 to 55 min. Previous studies using raw milk from commercial flocks showed that curd firmness (curd resistance to compression) at cutting point varied from approximately 82 to 115 g during Idiazabal cheese processing season (Nájera et al., 2009; Abilleira et al., 2010). As expected, all cheesemakers used a coagulation temperature close to $30^{\circ} \mathrm{C}$, and we found very few significant $(P \leq 0.05)$ differences for curd $\mathrm{pH}$ among artisanal dairies (mean $\mathrm{pH}$ values ranged between 6.49 and 6.65). Both temperature and $\mathrm{pH}$ parameters are known to strongly affect milk coagulation process (Nájera et al., 2003), but the cheesemakers collaborating in our study managed these 2 factors in a similar way during the cheesemaking. As well as curd $\mathrm{pH}$ values, we found no significant differences $(P>0.05)$ in the $\mathrm{pH}$ of stirred curd grains among dairies (Table 1). Furthermore, $\mathrm{pH}$ values did not significantly change from curd to stirred curd grains (up to 0.09), and, in consequence, curd grain syneresis was not influenced by acidification during stirring process.

Due to the specific conditions established by Idiazabal PDO rules (Ministerio de Agricultura, Pesca y Alimentación, 1993), temperature settings during the cutting and stirring processes were very similar $(P>$
0.05 ) for all of the artisanal dairies. However, other technical settings were established by the cheesemaker and, hence, we noted significant $(P \leq 0.05)$ variations in time and rotation speed for curd cutting and stirring among dairies (Table 1). Cutting time ranged between 3 and $28 \mathrm{~min}$ and stirring time varied from 9 to $51 \mathrm{~min}$. The cutting and stirring speeds were also highly variable factors among artisanal dairies (Table 1 ). The lowest speed used for both cutting and stirring was used in the artisanal dairy with the highest milk volume processed, but no significant correlation ( $<<0.20 ; P>0.05)$ was observed between milk volume and cutting or stirring speed for the other dairies (milk volume $<1,000 \mathrm{~L}$ ). The highest value of total revolutions used during cheesemaking corresponded to the dairy that extended the time for cutting and stirring up to approximately $70 \mathrm{~min}$ (dairy 2 ), whereas the rest of the artisanal dairies set the time below $40 \mathrm{~min}$ and the total revolutions used for cheesemaking were less than 850 (Table 1). As discussed below, this conditioned the curd grain syneresis process and, in consequence, the particle size of FCG and SCG was strongly affected (Table 2). In general, the wide scale of cutting and stirring technical settings employed by the cheesemakers showed the current variability and also the challenges and opportunities to optimizing the cheesemaking process in the artisanal dairies.

\section{Curd Grain Size}

Table 2 shows the mean, standard deviation, and median area values of the extracted FCG and SCG measured by image analysis from the 3 cheese productions carried out during Idiazabal cheese processing season in each artisanal dairy. Perimeter and Feret's diameter of curd grains were also measured (data not shown) and high statistical correlation $(r>0.92 ; P \leq 0.001)$ was found between these parameters and particle area. Accordingly, particle surface area was selected as the most representative parameter of curd grain size. As could be expected, cheese production effect and $D \times C P$ interaction term were statistically significant $(P \leq 0.001)$ for a particle area for both FCG and SCG due to the high intradairy variability in technical parameters used for cheesemaking, particularly in the cutting and stirring time and rotation speed as well as the milk volume handled by cheesemakers (Table 1). However, regardless of this intradairy variability during the cheese processing season, significant differences $(P \leq 0.05)$ were found in FCG and SCG areas among artisanal dairies depending mainly on cutting and stirring settings used for cheesemaking. Regarding the cutting step, FCG mean area values ranged from 10.01 to $43.11 \mathrm{~mm}^{2}$ and median values ranged from 6.73 to $32.18 \mathrm{~mm}^{2}$, showing 


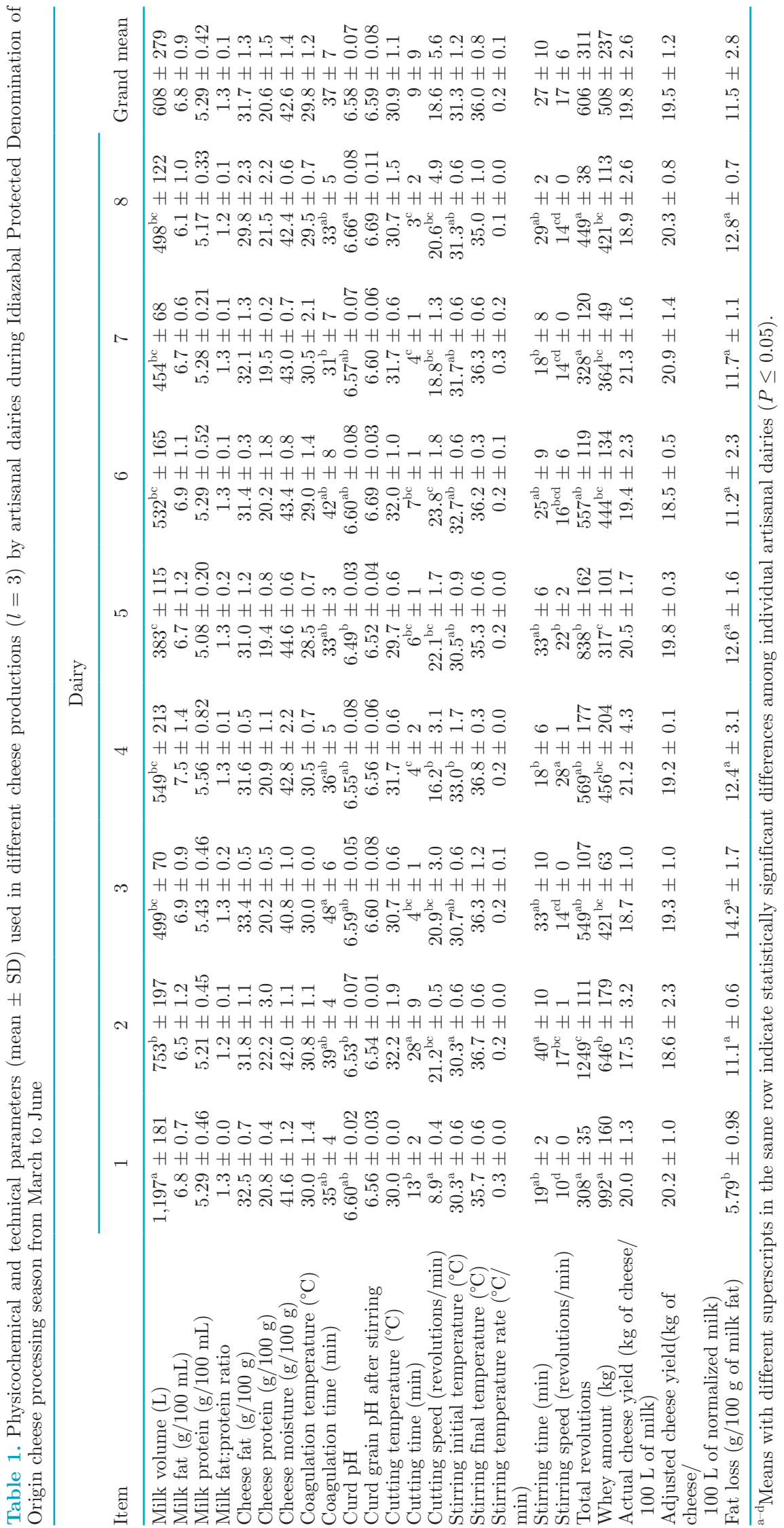


great differences $(P \leq 0.05)$ among artisanal dairies. These differences indicated that the particle area for both FCG was smaller as cutting revolutions increased ( $\mathrm{r} \geq|0.50| ; P \leq 0.01$ ), for example in the case of dairies 2 and 7 , for which adjusted cheese yield was also significantly different (Tables 1 and 2). Mean Feret's diameter values of FCG varied from 4.10 to $8.40 \mathrm{~mm}$, confirming, in general, the compliance with the curd grain diameter after the cutting process specified in the Idiazabal PDO cheese regulation (between 5 and $10 \mathrm{~mm}$ ); however, the curd grain size variability within the same cheese production was very high, as discussed later.

Regarding the stirring step, SCG mean area values ranged from 8.59 to $25.79 \mathrm{~mm}^{2}$ and median values ranged from 6.10 to $16.50 \mathrm{~mm}^{2}$, also showing great differences $(P \leq 0.05)$ among artisanal dairies (Table 2$)$. In comparison to FCG, overall variability (values range amplitude) for SCG size parameters decreased due to the shrinkage of the particles (syneresis) with stirring and heating up to $36^{\circ} \mathrm{C}$. Figure 1 depicts the reduction rate of curd grain size parameters before and after stirring. Reduction rate mean values for area, perimeter, and Feret's diameter of curd grains were $1.86 \pm 0.77$, $1.33 \pm 0.26$, and $1.38 \pm 0.33$, respectively. The shrinkage of particles, and therefore the whey syneresis of curd grains, caused significant differences $(P \leq 0.01)$ in particle size parameters between FCG and SCG independent of stirring settings used in the artisanal dairies (Figure 1). In this sense, dairy 2 showed the smallest reduction rate for curd grain size $(1.26 \pm 0.40)$

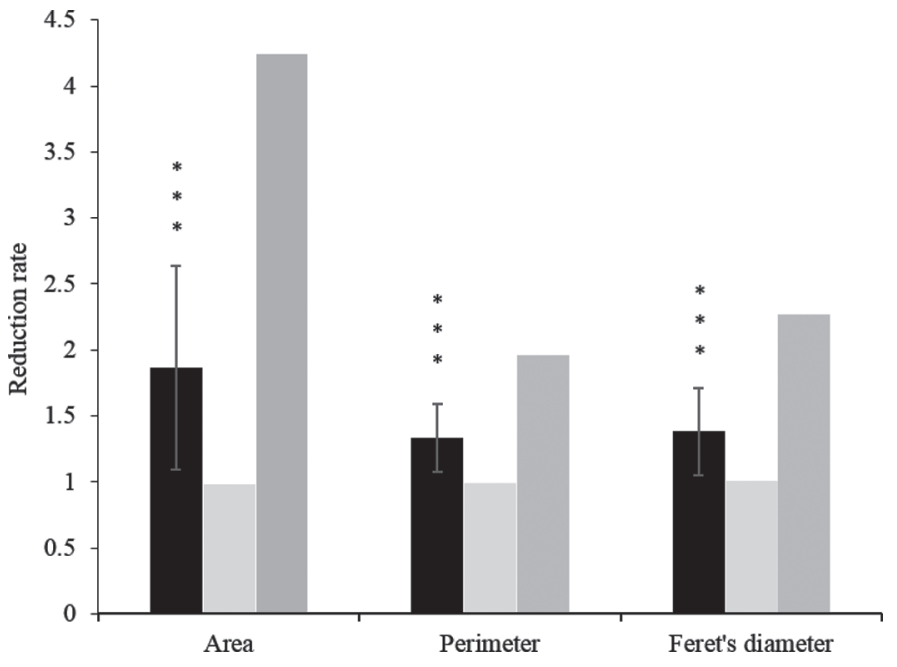

Figure 1. Reduction rate for area, perimeter, and Feret's diameter of curd grains during stirring. Bars depict mean (black), minimum (light gray), and maximum (dark gray) values. Error bars represent the overall SD of all dairies $(l=8)$ and cheese productions $(l=3)$. *** $P \leq 0.001$ in particle size parameters before and after stirring.

as expected, because despite the constant temperature (approximately $30^{\circ} \mathrm{C}$ ) the lengthening of the cutting time (20 min longer than the grand mean value of the cutting time; Table 1) led to an important part of the curd grain syneresis happening before stirring.

As mentioned above, both cutting and stirring conditions affected curd grain size, and relationships between technical parameters used by the cheesemakers and particle size were investigated. Linear relation-

Table 2. Mean, SD, and median area values $\left(\mathrm{mm}^{2}\right)$ of curd grains after cutting (FCG) and after stirring (SCG) obtained in different cheese productions $(l=3)$ by artisanal dairies during Idiazabal Protected Denomination of Origin cheese processing season from March to June

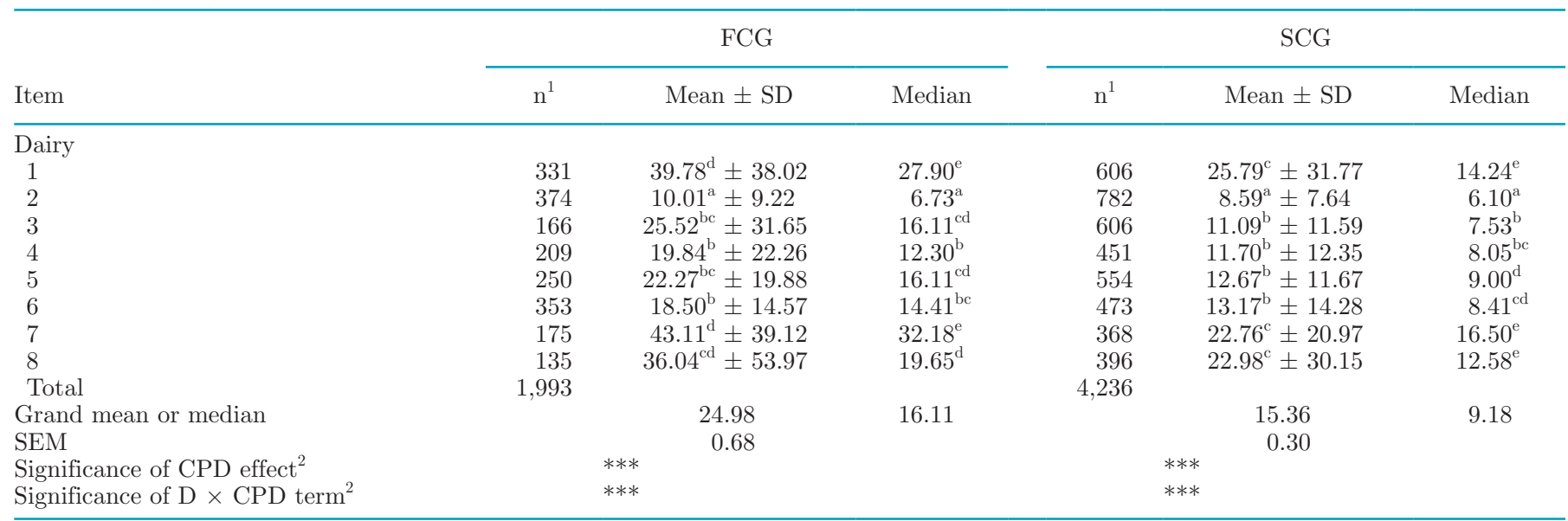

\footnotetext{
${ }^{\mathrm{a} e} \mathrm{Mean}$ and median values with different superscripts in the same column indicate statistically significant differences among individual artisanal dairies $(P \leq 0.05)$.

${ }^{1} \mathrm{n}=$ number of curd grains measured by image analysis.

${ }^{2} \mathrm{CPD}=$ cheese production; $\mathrm{D}=$ individual dairy.

$* * * P \leq 0.001$.
} 
ships were found between curd grain size parameters and the logarithm of total revolutions used during cheesemaking. Total revolutions included the total time used for cutting and stirring steps but not the stirring temperature rate, as it has been previously reported for cooked pressed cheeses (Iezzi et al., 2012) and heating contributes to casein aggregation and whey syneresis. However, Idiazabal PDO cheese artisanal dairies used similar initial and final stirring temperatures (from approximately 30 to $36^{\circ} \mathrm{C}$, respectively), and the stirring temperature rate did not significantly change among dairies (Table 1). Therefore, it could be estimated that the potential heating effect on curd grain syneresis was similar during cheesemaking in the artisanal dairies.

The linear regression models showed that the total revolutions had a significant effect $(P \leq 0.001)$ on the area, perimeter, and Feret's diameter, and that the percentages of explained variance were approximately $60 \%$ (Figure 2). The relationships pointed in the same direction: as the total revolutions increased, the curd grain size parameters decreased. These results agreed with those reported by Johnston et al. (1991), confirm- ing that curd particle size is determined not only by the cutting step but by a combination of cutting and stirring conditions. No direct correlation was observed in the present commercial study between curd grain parameters and cheese composition, probably due to the high intra- and interdairy variability; however, other authors reported lower cheese moisture when curd grain size was smaller (Johnston et al., 1991). Therefore, SCG size analysis could be a control point during cheesemaking to achieve uniform curd particle size as well as homogeneous fresh cheese moisture. On the other hand, as Table 2 shows, after the stirring step the artisanal dairies could be classified into 3 groups depending on SCG size (area): small $\left(<10 \mathrm{~mm}^{2}\right)$, medium (between 10 and $\left.20 \mathrm{~mm}^{2}\right)$, and large $\left(>20 \mathrm{~mm}^{2}\right.$ ) area. These data could also be useful to differentiate the dairies within Idiazabal cheese PDO depending on SCG size to optimize the cheesemaking conditions used by each cheesemaker, as consumers appreciate the artisanal process of small rural dairies, and therefore the intrinsic sensory properties of the artisanal cheeses and the differences between them. On the other hand,

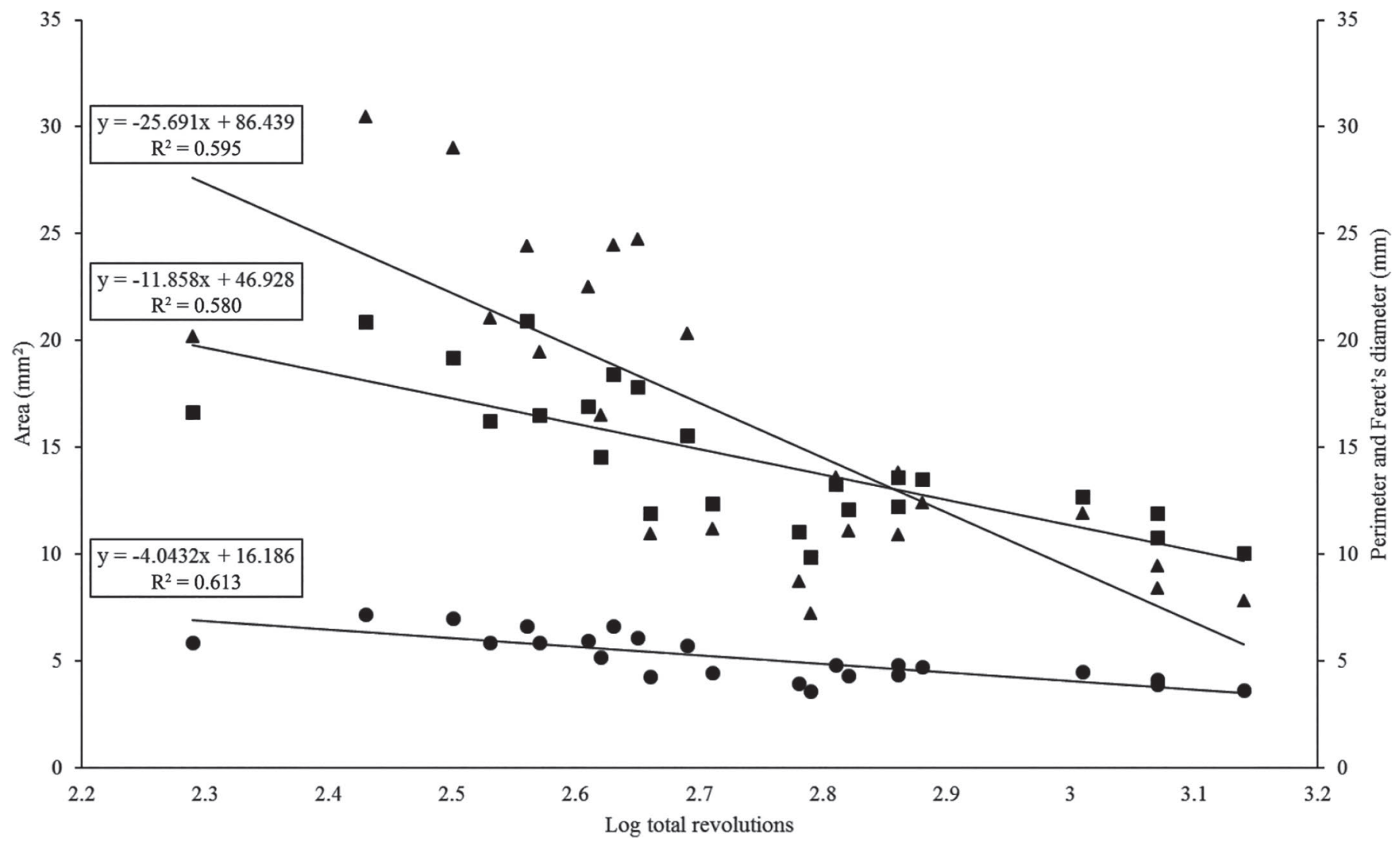

Figure 2. Linear relationship between area $(\boldsymbol{\Lambda})$, perimeter $(\boldsymbol{\square})$, and Feret's diameter $(\boldsymbol{\bullet})$ of curd grains and the log of total revolutions used during the cheesemaking $(l=3)$ in artisanal dairies $(l=8)$. 
Table 3. Mean values for particle size distribution parameters of curd grains after cutting (FCG) and after stirring (SCG) obtained in different cheese productions $(l=3)$ by artisanal dairies during the processing season for Idiazabal Protected Denomination of Origin cheese from March to June ${ }^{1}$

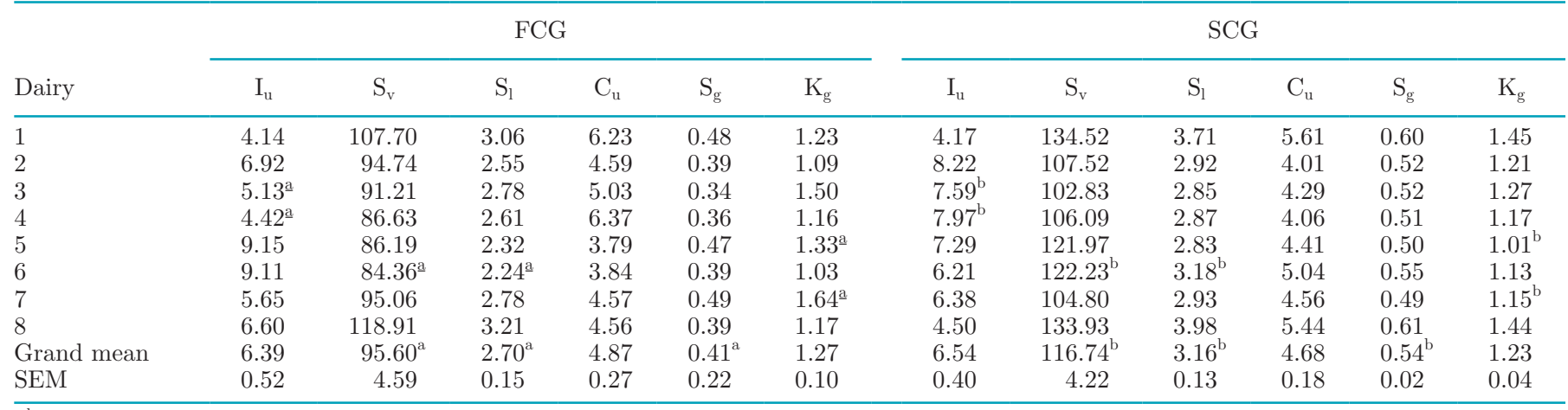

${ }^{\mathrm{a}, \mathrm{b}}$ Mean values with different superscripts in the same row indicate statistically significant differences between FCG and SCG particle size distribution parameters $(P \leq 0.05)$.

${ }^{1}$ The number of curd grains measured by image analysis in each dairy is detailed in Table $2 . \mathrm{I}_{\mathrm{u}}=$ uniformity index $\left(\mathrm{I}_{\mathrm{u}}=\mathrm{D}_{5} / \mathrm{D}_{90} \times 100\right) ; \mathrm{S}_{\mathrm{v}}=\operatorname{size}$ range variation coefficient $\left[\mathrm{S}_{\mathrm{v}}=\left(\mathrm{D}_{84}-\mathrm{D}_{16}\right) / 2 \mathrm{D}_{50} \times 100\right] ; \mathrm{S}_{1}=$ relative span $\left[\mathrm{S}_{1}=\left(\mathrm{D}_{90}-\mathrm{D}_{10}\right) / \mathrm{D}_{50}\right] ; \mathrm{C}_{\mathrm{u}}=$ coefficient of uniformity $\left(\mathrm{C}_{\mathrm{u}}=\mathrm{D}_{60} /\right.$ $\left.\mathrm{D}_{10}\right) ; \mathrm{S}_{\mathrm{g}}=$ graphic skewness $\left\{\mathrm{S}_{\mathrm{g}}=\left[\left(\mathrm{D}_{84}+\mathrm{D}_{16}-2 \mathrm{D}_{50}\right) / 2\left(\mathrm{D}_{84}-\mathrm{D}_{16}\right)\right]+\left[\left(\mathrm{D}_{95}+\mathrm{D}_{5}-2 \mathrm{D}_{50}\right) / 2\left(\mathrm{D}_{95}-\mathrm{D}_{5}\right)\right]\right\}$; $\mathrm{K}_{\mathrm{g}}=$ graphic kurtosis $\left\{\mathrm{K}_{\mathrm{g}}=\left[\left(\mathrm{D}_{95}-\right.\right.\right.$ $\left.\left.\left.\mathrm{D}_{5}\right) / 2.44\left(\mathrm{D}_{75}-\mathrm{D}_{25}\right)\right]\right\}$; where the $\mathrm{D}_{\mathrm{x}}$ is the xth percentile dimension of the area distribution in each dairy and cheese production.

these results can contribute to a deeper knowledge on the relationship between cutting and stirring conditions and curd grain size and the syneresis process.

\section{Curd PSD Analysis}

The PSD analysis was performed for curd grains after the cutting and stirring steps due to the high variability observed in the size of curd particles in the artisanal dairies. As reported, the higher or lower homogeneity of curd grain PSD after the cutting and stirring process could also affect the binding of curd grains during pressing, the moisture distribution, and texture of fresh cheese (Akkerman et al., 1993; Iezzi et al., 2012). Table 3 shows mean values for parameters used to assess the uniformity or unevenness of curd PSD after cutting and stirring in the artisanal dairies. All the PSD parameters confirmed that the curd grains obtained after the cutting and stirring steps were highly heterogeneous. The effect of curd syneresis was only statistically significant $(P \leq 0.05)$ for some PSD parameters and the effect was, as expected, dependent on the individual artisanal dairy. None of the dairies showed a clear improvement in all the PSD parameters. Moreover, some values (i.e., size range variation coefficient and relative span) indicated a slight increase of the heterogeneity after the stirring step, whereas the values of the uniformity distribution parameters (uniformity index and coefficient of uniformity) raised or lowered during curd grain syneresis. In contrast to our study, Iezzi et al. (2012) reported an enhanced PSD homogeneity after the cooking process for Italian cheeses by the relative span values, even with a high variability among dairies.
The lack of improvement and, in some cases, the impairment of the homogeneity of curd grains after stirring in Idiazabal PDO cheeses was probably due to the existence of a small amount of large SCG despite the general particle size reduction during stirring (Figure $3)$. This heterogeneity led to a smaller size reduction of the larger particles and a higher syneresis rate of the smaller particles during stirring. This agrees with other authors (Unger Grundelius et al., 2000; Dejmek and Walstra, 2004), who reported that the grain size was one of the most important factors determining the shrinkage of the curd grain during the initial stage (up to 80 min) due to Darcy's law.

The PSD graphic skewness and kurtosis were also measured for FCG and SCG. All artisanal dairies showed graphic skewness values higher than 0.30 and 0.49 for FCG and SCG, respectively (Table 3), classified by Folk and Ward (1957) as very positiveskewed values. This meant that FCG distribution was characterized by a large amount of small curd particles whose number increased $(P \leq 0.05)$ during stirring. Concerning kurtosis values, PSD could be classified from mesokurtic to very leptokurtic (Folk and Ward, 1957), confirming again the presence of a high number of small particles in both FCG and SCG.

Despite the fact that each artisanal dairy had different behavior in curd PSD parameters, the general trend suggested that PSD was mainly determined by cutting, whereas stirring could cause slight changes in PSD most likely due to a higher size reduction and increased amount of small particles compared to the larger curd grains. These results agree with those found by other authors, who reported that technical settings 
used during cutting and stirring determines the curd grain size after stirring, whereas curd PSD is essentially derived from the cutting action (Johnston et al., 1991; Iezzi et al., 2012).

\section{Curd Grain Shape}

Curd grain shape has not been a widely studied feature mostly due to the sampling methods used, especially the sieving method (Johnston et al., 1991). In general, the shape of curd grains is usually described as irregular, as particles do not fit regular geometric shapes such as circles, ellipses, rectangles, squares, or triangles, and this makes it difficult to apply some known image analysis methods to identify and classify them (Igathinathane et al., 2008). Kammerlehner

\section{a}

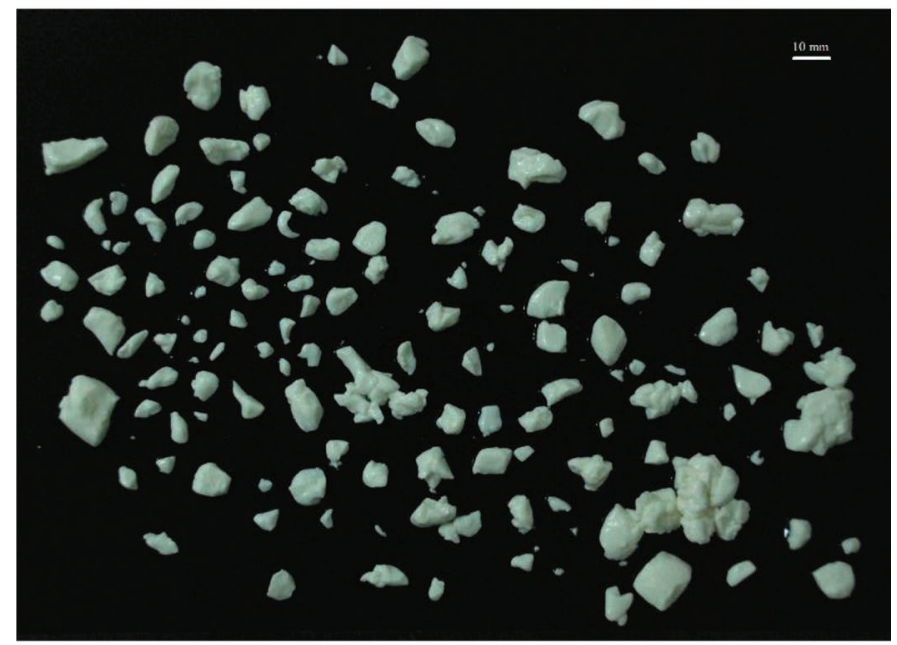

b

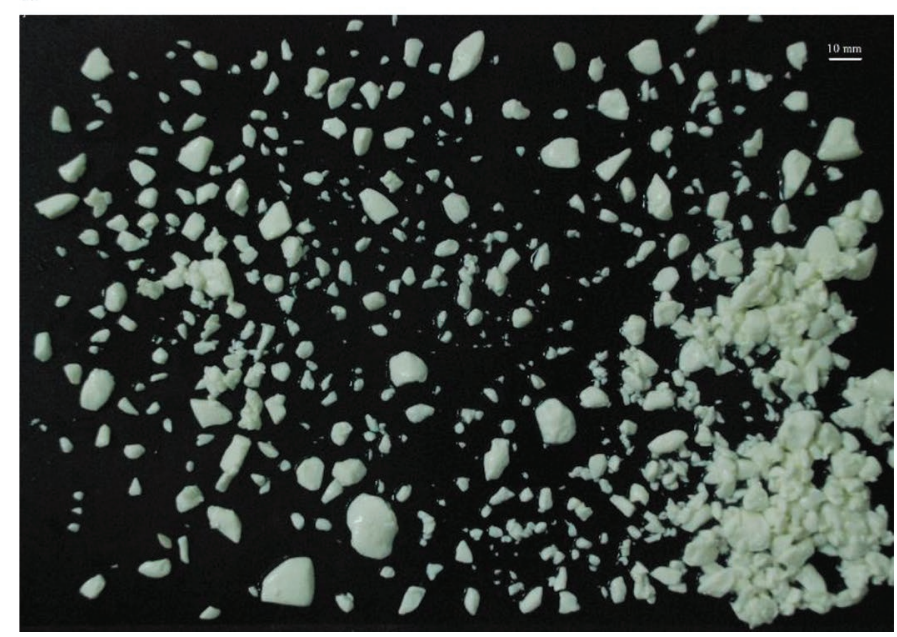

Figure 3. Two-dimensional digital image of curd grains after cutting (a) and stirring (b) from the same cheese production carried out in an artisanal cheese dairy. The scale bars are $10 \mathrm{~mm}$ in length.
(2009) described curd grain shapes obtained in several cheese types as comparable to walnuts, hazelnuts, corn, barley, and others, whereas Akkerman (1992) characterized them as angular, rounded, or disc-shaped. More recently, Iezzi et al. (2012) used the elongation as a shape indicator of curd grains. In the present study, a major effort has been made to characterize in-depth the irregular shape of the curd grains after the cutting and stirring processes during cheesemaking. Table 4 shows the mean values for RAR, RTY, and CTY shape parameters to describe, respectively, elongation, rectangularity, and circularity degree of the curd grains after cutting (FCG) and stirring (SCG) during cheesemaking in artisanal dairies. In general, curd grains showed irregular shapes very different from one another (Figure 3), with slightly higher values of circularity than elongation or rectangularity (see grand mean values for RAR, RTY, and CTY in Table 4). Significant differences $(P \leq 0.05)$ were found for cheese production and individual dairy effects and $D \times C P$ interaction term in most particle shape parameters of both FCG and SCG. As previously mentioned for particle size parameters, these results pointed out the high intra-and interdairy variability in technical parameters used for cheesemaking. In addition, especially for particle shape parameters, the differences in the design of cutting and stirring tools among artisanal dairies were most likely responsible for changes in curd grain shape. The surface area and shape of the cutting and stirring devices, and the number and arrangement of the wires, could be important design factors affecting curd grain breakdown. In this regard, it has been suggested that rotating cutting tools lead to several shapes distinct to cube-shaped curd grains (Kammerlehner, 2009). However, contrary to what was observed for curd grain size parameters, no clear pattern related to technical parameters during cheesemaking explained differences in particle shape parameters of both FCG and SCG among artisanal dairies (Tables 1 and 4).

On the other hand, in spite of the high variability observed, significant differences $(P \leq 0.001)$ were found in RAR and RTY between FCG and SCG, which meant that changes in curd grain shape occurred during stirring. Curd grain RAR showed a decreasing trend during stirring in all dairies, meaning that particles were slightly more elongated after stirring, whereas RTY pointed at different directions depending on the dairy (Table 4), being indicative of a strong $D \times S$ interaction $(P \leq 0.05)$. Iezzi et al. (2012) also measured the elongation of the curd particles in Italian cooked pressed cheeses, but no changes on this parameter were reported before and after the cooking, although it should be noted that particles showed high elongation values in FCG and SCG. In summary, cutting and 
stirring processes caused the breaking and shrinkage of particles, in particular the stirring step could affect the final curd grain shape and, consequently, the binding of curd grains during pressing as well as the formation and texture of fresh cheese (Akkerman et al., 1993; Iezzi et al., 2012).

\section{Relationship Between Cheese Yield and Technological Parameters}

As multiple parameters were involved, a principal component analysis was performed to investigate the relationships between the actual cheese yield, fat loss, curd grain size and shape parameters, and technological conditions used in the artisanal dairies during cheese processing. Two principal components were extracted explaining the $67.82 \%$ of the total variance (Figure 4 ). Principal component 1 was highly correlated (factor loadings $>|0.7|$ ) with FCG and SCG size parameters and cutting revolutions and moderately (factor loading $\sim|0.5|)$ with actual cheese yield and stirring revolutions. Therefore, actual cheese yield and FCG and SCG size parameters were inversely correlated with the cutting and stirring revolutions used during cheesemaking. Principal component 2 was highly correlated (factor loading $>|0.7|$ ) with SCG and FCG elongation and fat loss and, to a lesser extent, with stirring revolutions and SCG size parameters (factor loading $\sim 0.6$ ). Curd grain elongation was positively correlated with stirring revolutions, meaning that the stirring process could be primarily responsible for the final shape of the curd grains, as discussed above. Interestingly, fat loss was correlated with these parameters, indicating that when higher stirring revolutions were used during cheesemaking, fat release was enhanced. This agrees with other authors that demonstrated that an insufficient cutting process leads to the shattering of curd particles during stirring and, consequently, increased fat losses (Johnston et al., 1991). The biplot graph in Figure 4 shows high intra- and interdairy variability during the cheese processing season, but although some artisanal dairies showed a major spread between their own cheese productions (dairies 2,4 , or 8 ), others presented quite homogeneous results (dairies 1, 5, or 6).

\section{CONCLUSIONS}

Two-dimensional image analysis appears to be a useful tool to characterize and monitor the curd grain syneresis during cheesemaking. The wide scale of technical settings used in commercial cheese manufacturing caused differences in curd grain size and shape among artisanal dairies. Regardless of the high variability observed during the cheese production season, cutting and stirring conditions were correlated with curd grain size and shape parameters, particle size distribution, fat loss, and cheese yield. Higher values of total revolutions used by cheesemakers during the cutting and stirring steps significantly reduced the curd grain size. However, the stirring process was the main responsible for the fat loss during cheesemaking, probably due to the curd shattering effect of overdone revolutions. However,

Table 4. Mean \pm SD values for particle shape parameters of curd grains after cutting (FCG) and after stirring (SCG) obtained in different cheese productions $(l=3)$ by artisanal dairies during Idiazabal Protected Denomination of Origin cheese production season from March to June ${ }^{1}$

\begin{tabular}{|c|c|c|c|c|c|c|}
\hline Item & \multicolumn{3}{|c|}{ FCG } & \multicolumn{3}{|c|}{ SCG } \\
\hline 2 & $0.706^{\mathrm{ab}} \pm 0.135$ & $0.689^{\mathrm{ab}} \pm 0.067$ & $0.774^{\mathrm{bc}} \pm 0.076$ & $0.701^{\mathrm{bc}} \pm 0.128$ & $0.692^{\mathrm{bc}} \pm 0.063$ & $0.777^{\mathrm{c}} \pm 0.077$ \\
\hline 3 & $0.746^{\mathrm{c}} \pm 0.123$ & $0.712^{\mathrm{c}} \pm 0.052$ & $0.787^{\mathrm{bc}} \pm 0.083$ & $0.705^{\mathrm{bc}} \pm 0.140$ & $0.694^{\mathrm{bc}} \pm 0.064$ & $0.784^{\text {cd }} \pm 0.074$ \\
\hline 4 & $0.737^{\mathrm{bc}} \pm 0.127$ & $0.699^{\mathrm{bc}} \pm 0.060$ & $0.775^{\mathrm{bc}} \pm 0.075$ & $0.707^{\mathrm{bc}} \pm 0.131$ & $0.701^{\mathrm{c}} \pm 0.063$ & $0.795^{\mathrm{d}} \pm 0.075$ \\
\hline 7 & $0.739^{b c} \pm 0.129$ & $0.706^{\mathrm{bc}} \pm 0.065$ & $0.769^{\mathrm{bc}} \pm 0.069$ & $0.693^{\mathrm{ab}} \pm 0.138$ & $0.687^{\mathrm{ab}} \pm 0.065$ & $0.726^{\mathrm{a}} \pm 0.099$ \\
\hline 8 & $0.708^{\mathrm{ab}} \pm 0.131$ & $0.704^{\mathrm{bc}} \pm 0.061$ & $0.754^{\mathrm{ab}} \pm 0.120$ & $0.705^{\mathrm{bc}} \pm 0.130$ & $0.698^{\mathrm{bc}} \pm 0.059$ & $0.776^{\mathrm{c}} \pm 0.074$ \\
\hline Grand mean & 0.718 & 0.696 & 0.771 & 0.699 & 0.691 & 0.771 \\
\hline SEM & 0.003 & 0.001 & 0.002 & 0.002 & 0.001 & 0.001 \\
\hline $\begin{array}{l}\text { Significance of } \\
\text { CPD effect }\end{array}$ & NS & NS & $* * *$ & * & $* * *$ & $* * *$ \\
\hline $\begin{array}{l}\text { Significance of } \\
\mathrm{D} \times \mathrm{CPD} \text { term }\end{array}$ & NS & $*$ & $* * *$ & $* *$ & $* *$ & $* * *$ \\
\hline
\end{tabular}

\footnotetext{
${ }^{a-c}$ Mean values with different superscripts in the same column indicate statistically significant differences among individual artisanal dairies $(P$ $\leq 0.05)$.

${ }^{1}$ The number of curd grains measured by image analysis in each dairy is detailed in Table 2 . RAR $=$ reciprocal aspect ratio; RTY $=$ rectangularity $; \mathrm{CTY}=$ circularity $; \mathrm{CPD}=$ cheese production; $\mathrm{D}=$ individual dairy.

${ }^{*} P \leq 0.05,{ }^{* *} P \leq 0.01,{ }^{* * *} P \leq 0.001$.
} 


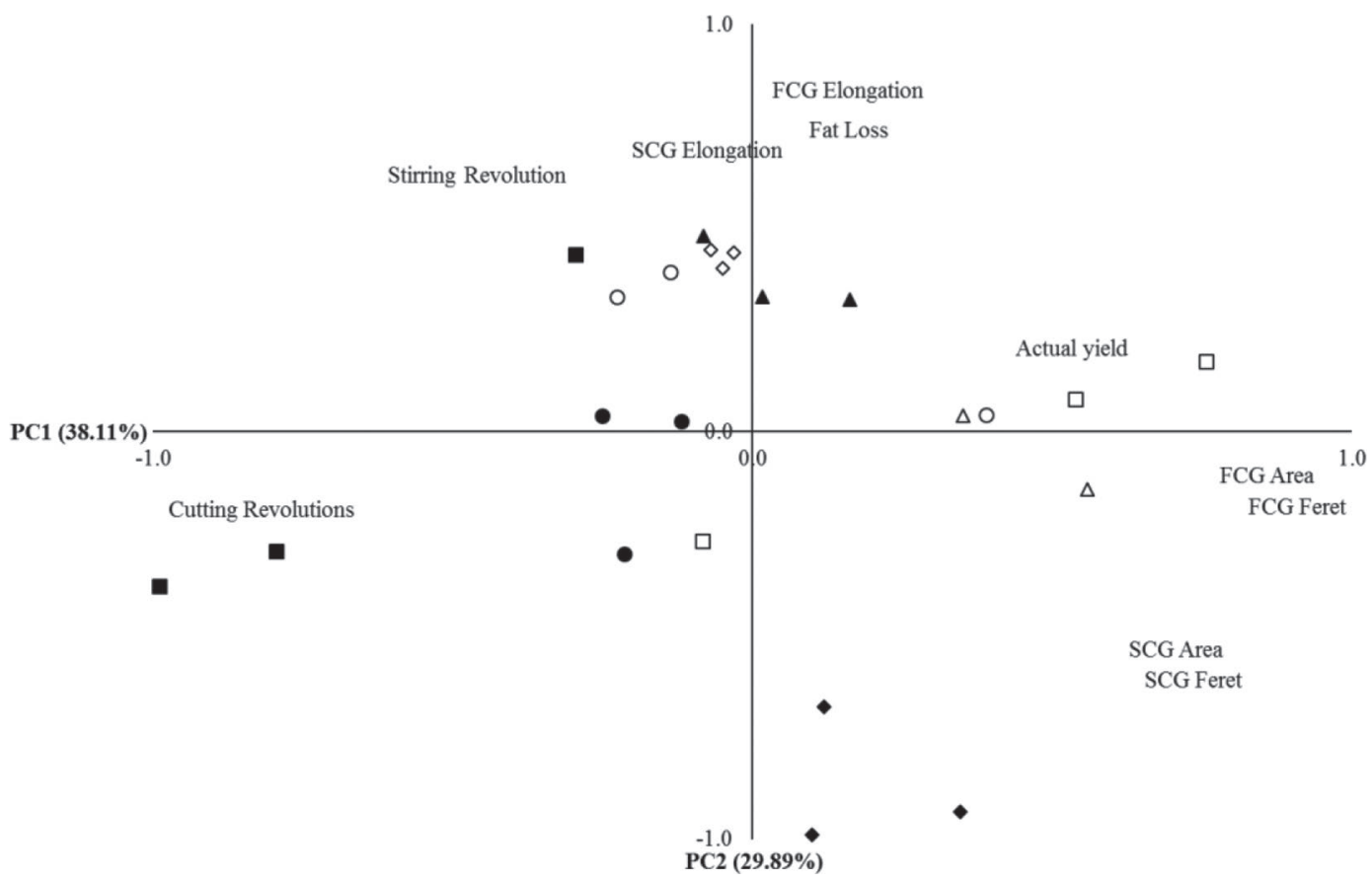

Figure 4. Principal component (PC) analysis biplot depicting variable loadings and cheese production distribution in the 2-dimensional coordinate system defined by PC1 and PC2. $\bullet$ dairy $1 ; \boldsymbol{\square}=$ dairy $2 ; \boldsymbol{\Lambda}=$ dairy $3 ; \bigcirc=$ dairy $4 ; \diamond=$ dairy $5 ; \bullet=$ dairy $6 ; \Delta=$ dairy $7 ; \square=$ dairy $8 . \mathrm{FCG}=$ fresh curd grain; $\mathrm{SCG}=$ stirred curd grain.

no clear pattern related to technical settings was found to explain differences in particle shape parameters during curd grain syneresis, even though stirring showed to be the main factor responsible for the final shape of curd grains. In general, curd particle size distributions were highly heterogeneous, with an increasing number of small particles during stirring and a variable amount of large grains initially formed by curd cutting. Even though each artisanal dairy showed a different behavior in particle size distribution, the general trend suggested that curd syneresis during the stirring step had a very small effect on curd particle size distribution. The data reported in our study may contribute to improving and controlling the cheesemaking process in small artisanal dairies where the role of the cheesemaker is crucial. Furthermore, using the 2-dimensional image analysis approach in controlled experimental designs could help in the interpretation of the effect of interactions between milk composition and cheesemaking technical settings on curd grain parameters, cheese composition, and yield.

\section{ACKNOWLEDGMENTS}

The authors thank the cheesemakers of Idiazabal PDO for collaborating with this study. Financial support was provided by the University of the Basque Country (UPV/EHU) (PA16/04) and the Basque Government
(IT944-16). A. Aldalur thanks the Basque Government (Vitoria-Gasteiz, Spain) for the predoctoral fellowship.

\section{REFERENCES}

Abilleira, E., M. Virto, A. I. Nájera, J. Salmerón, M. Albisu, F. J. Pérez-Elortondo, J. C. Ruiz de Gordoa, M. de Renobales, and L. J. R. Barron. 2010. Effects of seasonal changes in feeding management under part-time grazing on the evolution of the composition and coagulation properties of raw milk from ewes. J. Dairy Sci. 93:3902-3909.

Akkerman, J. C. 1992. Drainage of curd. PhD Thesis. Wageningen University and Research, Wageningen, the Netherlands.

Akkerman, J. C., R. O. Lewis, and P. Walstra. 1993. Fusion of curd grains. Neth. Milk Dairy J. 47:137-144.

Bustamante, M., F. Chávarri, A. Stantisteban, G. Ceballos, I. Hernández, M. J. Miguélez, I. Aranburu, L. J. R. Barron, M. Virto, and M. de Renobales. 2000. Coagulating and lipolytic activities of artisanal lamb rennet pastes. J. Dairy Res. 67:393-402.

Dejmek, P., and P. Walstra. 2004. The syneresis of rennet-coagulated curd. Pages 71-103 in Cheese: Chemistry, Physics and Microbiology. Vol. 1. General Aspects. P. F. Fox, T. P. Guinee, T. M. Cogan and P. L. H. McSweeney, ed. Elsevier Applied Science, London, UK.

Du, C., and D. Sun. 2004. Recent developments in the applications of image processing techniques for food quality evaluation. Trends Food Sci. Technol. 15:230-249.

European Commission. 2015. Commission implementing Regulation (EU) 2015/1077 of 1 July 2015 approving non-minor amendments to the specification for a name entered in the register of protected designations of origin and protected geographical indications (Idiazabal (PDO). Accessed Dec. 18, 2017. http://data.europa.eu/eli/ reg_impl/2015/1077/oj.

Everard, C. D., D. J. O'Callaghan, M. J. Mateo, C. P. O'Donnell, M. Castillo, and F. A. Payne. 2008. Effects of cutting intensity and 
stirring speed on syneresis and curd losses during cheese manufacture. J. Dairy Sci. 91:2575-2582.

Folk, R. L., and W. C. Ward. 1957. Brazos River bar: A study in the significance of grain size parameters. J. Sediment. Petrol. 27:3-26.

Guinee, T. P., B. T. O'Kennedy, and P. M. Kelly. 2006. Effect of milk protein standardization using different methods on the composition and yields of Cheddar cheese. J. Dairy Sci. 89:468-482.

Idiazabal PDO. 2017. Cheese-makers. Accessed Dec. 12, 2017. http:// www.quesoidiazabal.eus/productores.

Iezzi, R., F. Locci, R. Ghiglietti, C. Belingheri, S. Francolino, and G. Mucchetti. 2012. Parmigiano Reggiano and Grana Padano cheese curd grains size and distribution by image analysis. LWT Food Sci. Technol. 47:380-385.

Igathinathane, C., L. O. Pordesimo, E. P. Columbus, W. D. Batchelor, and S. R. Methuku. 2008. Shape identification and particles size distribution from basic shape parameters using ImageJ. Comput. Electron. Agric. 63:168-182.

Igathinathane, C., L. O. Pordesimo, E. P. Columbus, W. D. Batchelor, and S. Sokhansanj. 2009. Sieveless particle size distribution analysis of particulate materials through computer vision. Comput. Electron. Agric. 66:147-158.

ISO/IDF. 2004. Cheese and processed cheese-Determination of the total solids content. ISO 5534:2004/ IDF 4: 2004. International Standardisation Organisation, Geneva, Switzerland.

ISO/IDF. 2008a. Milk—Determination of fat content. ISO 2446:2008/ IDF 226:2008. International Standardisation Organisation, Geneva, Switzerland.

ISO/IDF. 2008b. Cheese-Determination of fat content-Butyrometer for Van Gulik method. ISO 3432:2008/ IDF 221:2008. International Standardisation Organisation, Geneva, Switzerland.

ISO/IDF. 2008c. Processed cheese products-Determination of nitrogen content and crude protein calculation - Kjeldahl method. ISO 17837:2008/ IDF 25:2008. International Standardisation Organisation, Geneva, Switzerland.

ISO/IDF. 2014. Milk and milk products-Determination of nitrogen content-Part 1: Kjeldahl principle and crude protein calculation. ISO 8968-1:2014/ IDF 20-1:2014. International Standardisation Organisation, Geneva, Switzerland.

Jablonka, M. S., and P. A. Munro. 1985. Particle size distribution and calcium content of batch-precipitated acid casein curd: effect of precipitation temperature and pH. J. Dairy Res. 52:419-428.
Johnston, K. A., F. P. Dunlop, and M. F. Lawson. 1991. Effects of speed and duration of cutting in mechanized Cheddar cheese. J. Dairy Res. 58:345-354.

Johnston, K. A., M. S. Luckman, H. G. Lilley, and B. M. Smale. 1998. Effect of various cutting and stirring conditions on curd particle size and losses of fat to the whey during Cheddar cheese manufacture in Ost vats. Int. Dairy J. 8:281-288.

Kammerlehner, J. 2009. Rennet cheese (cow's milk cheese). Pages 43-624 in Cheese Technology. J. Kammerlehner, ed. Josef Kammerlehner, Freising, Germany.

Kosikowski, F. V. 1963. Some distribution patterns of cottage cheese particles and conditions contributing to curd shattering. J. Dairy Sci. 46:391-395.

Mateo, M. J., D. J. O'Callaghan, A. A. Gowen, and C. P. O'Donnell. 2010. Evaluation of a vat wall-mounted image capture system using image processing techniques to monitor curd moisture during syneresis with temperature treatments. J. Food Eng. 99:257-262.

Ministerio de Agricultura, Pesca y Alimentación. 1993. Reglamento de la Denominación de Origen Idiazabal y su Consejo Regulador. Boletín Oficial del Estado 289:34591-34596.

Nájera, A. I., L. J. R. Barron, P. Ribeiro, F. Pélissier, E. Abilleira, F. J. Pérez-Elortondo, M. Albisu, J. Salmerón, J. C. Ruiz de Gordoa, M. Virto, L. Oregi, R. Ruiz, and M. de Renobales. 2009. Seasonal changes in the technological and compositional quality of ewe's raw milks from commercial flocks under part-time grazing. J. Dairy Res. 76:301-307.

Nájera, A. I., M. De Renobales, and L. J. R. Barron. 2003. Effects of $\mathrm{pH}$, temperature, $\mathrm{CaCl}_{2}$ and enzyme concentrations on the rennetclotting properties of milk: a multifactorial study. Food Chem. 80:345-352.

Rüegg, M., and U. Moor. 1987. The size distribution and shape of curd granules in traditional swiss hard and semi-hard cheeses. Food Struct. 6:35-46.

Unger Grundelius, A., K. Lodaite, K. Östergren, M. Paulsson, and P. Dejmek. 2000. Syneresis of submerged single curd grains and curd rheology. Int. Dairy J. 10:489-496. 